\title{
Weight bias: a call to action
}

\author{
Angela S. Alberga ${ }^{1 *}$, Shelly Russell-Mayhew ${ }^{1 \dagger}$, Kristin M. von Ranson ${ }^{2+}$ and Lindsay McLaren ${ }^{3+}$
}

\begin{abstract}
Weight-related issues (including excess weight, disordered eating and body concerns) are often considered as comprising distinct domains of 'obesity' and 'eating disorders'. In this commentary we argue that the concept of weight bias is an important variable when considering wellbeing across the spectrum of weight-related issues. We make the following six points in support of this argument: i) weight bias is common and has adverse health consequences, ii) shaming individuals for their body weight does not motivate positive behaviour change, iii) internalized weight bias is particularly problematic, iv) public health interventions, if not carefully thought out, can perpetuate weight bias, v) weight bias is a manifestation of social inequity, and vi) action on weight bias requires an upstream, population-level approach. To achieve sustainable reductions in weight bias at a population level, substantive modifications and collaborative efforts in multiple settings must be initiated. We provide several examples of population-level interventions to reduce weight bias.
\end{abstract}

Keywords: Weight stigma, Weight prejudice, Overweight, Eating behaviours

\section{Background}

"My therapist tells me not to talk about my weight and that my body is fine. But my doctor keeps weighing me and says that I need to lose weight', Ms. Schaefer said" (New York Times, October 10, 2013).

This quote illustrates a traditional disjoint in perspectives between practitioners in the fields of obesity and eating disorders [1], with different research priorities and approaches to prevention and management. However, a growing body of scholarship acknowledges that these weight-related domains are in fact related: obesity and eating disorders co-occur in individuals [2] and have risk factors in common [3]. It has been suggested that an integrative approach to weight-related issues, which merges knowledge from the fields of obesity and eating disorders, is central to effective prevention [4-6]. In this commentary we argue that the concept of weight bias is an important variable to consider in an integrative approach to wellbeing across the spectrum of weightrelated issues. Although there are significant literatures devoted to obesity and eating disorders, reviewing those literatures is beyond the scope of this paper. Rather, our focus is to address weight bias and offer potential population-level interventions to reduce it.

Weight bias is defined as "negative weight-related attitudes, beliefs, assumptions and judgments toward individuals who are overweight and obese" [7]. We extend this definition to include individuals of low as well as high weights. Weight-related issues include obesity and eating disorders, but importantly also include disordered eating and non- or sub-clinical variants or symptoms, such as overweight, body image dissatisfaction, restrained eating, disinhibited eating, emotional eating, and compensatory behaviors. The causes of weightrelated issues are complex and multi-factorial [8]. For the purpose of this paper, we emphasize the important role played by social, economic, and political influences $[9,10]$. Though individual agency plays a role, fixation on individuals' responsibility for weight serves to oversimplify and overstate [11].

There are at least six reasons that weight bias provides a useful and potentially powerful focal point for an integrated approach to wellbeing across the spectrum of weight-related issues.

* Correspondence: aalberga@ucalgary.ca

${ }^{\dagger}$ Equal contributors

${ }^{1}$ Werklund School of Education, University of Calgary, 2500 University Dr NW,

T2N 1N4 Calgary, AB, Canada

Full list of author information is available at the end of the article 
(1) Weight bias is common and has adverse health consequences

Weight bias impacts people across the weight spectrum $[12,13]$ and has increased over time [14]. People classified as 'overweight' or 'obese' have been shamed for their high weight $[15,16]$. There is also some evidence that adolescents categorized as 'underweight' [16] and individuals with eating disorders (e.g., anorexia, bulimia nervosa and binge eating disorder) have experienced weight bias [13]. Weight bias reflects, in part, that unlike other conditions, body weight is a physical characteristic that is visible. Weight bias has been associated with adverse health outcomes including anxiety, stress, depression, low self-esteem and body image issues [15, 17, 18]. Though disease consequences and mortality [19-21] of very high levels of excess weight have been documented, it has been proposed that the stigma associated with weight may actually be causing some of the negative health outcomes associated with excess weight rather than the excess weight itself [22], including increased mortality risk [23]. There is a need to better balance these two sets of consequences when addressing weightrelated issues.

\section{(2) Shaming individuals for their body weight does not motivate positive behaviour change}

Evidence indicates that shaming individuals with weightrelated issues does not motivate positive behaviour changes. To the contrary, experiencing weight bias could lead to the development of eating disorders and/or obesity. For example, individuals with obesity experiencing weight stigma often turn to unhealthy eating behaviors in line with eating disorder symptomatology, such as fasting, extreme dieting, frequent episodes of binge eating, and compulsive exercise [24-26]. Experiencing weight bias can also promote the avoidance of exercise (e.g., avoiding exercising in public for fear of being shamed for their weight) [27, 28] and maladaptive eating habits (e.g., binge eating related to the emotional stress of experiencing bias) $[29,30]$ that could promote weight gain.

\section{(3) Internalized weight bias is particularly problematic}

Internalized weight bias, defined as individuals' belief that they deserve the stigma and discriminatory treatment they experience as a result of having overweight or obesity [31], is particularly worrisome. People with eating disorders typically report high levels of internalized weight bias wherein they have an intense fear of being fat and a fear that being fat would negatively affect their life [32]. People with obesity also experience internalized weight bias [17]. These observations illustrate how weight bias is implicated across the spectrum of weightrelated issues, but may play different roles and manifest in different ways. Internalized weight bias is strongly associated with psychological maladjustment and eating pathology, including depression, poor body image [20], low self-esteem, avoidance of preventive health care [15] and lack of engagement in primary health care settings [33].

\section{(4) Public health interventions, if not carefully thought out, can perpetuate weight bias}

A weight-centric approach, in which weight is viewed as a proxy for health and beauty, has contributed to individuals with overweight or obesity experiencing weight bias and discrimination with increasing frequency and intensity [26]. Though adverse health correlates of obesity such as morbidity [34] and mortality [23] have been documented, the health implications associated with lower levels of "excess weight" are not clear and may be overstated [19]. It is not clear whether or the extent to which the adverse psychological and physical consequences of obesity are related to excess weight itself and/or weight bias. There is evidence to suggest that negative psychological outcomes are linked to experiencing weight bias even after controlling for age, gender, obesity onset and body mass index $[35,36]$. The focus on the health consequences of obesity has led to public 'fat panic' [25] through media portrayals and public health policies, programs, and campaigns [37] that glamorize thinness and demonize fatness. For example, the Children's Healthcare of Atlanta, U.S.A. launched Strong4Life, described as "a wellness movement designed to ignite societal change and reverse the epidemic of childhood obesity and its associated diseases in Georgia". This controversial childhood obesity public "health campaign" used images of children with obesity on billboards and websites with captions such as "Warning: Big bones didn't make me this way, big meals did" and "Warning: chubby kids may not outlive their parents". Such initiatives have been criticized for their weightstigmatizing messages [12]. Puhl et al. also surveyed a nationally representative sample of US adults to determine how obesity-related public health media campaigns are ranked. Participants responded least favorably to the messages that were publicly criticized for their stigmatizing content and showed fewer intentions to comply with the message content [38]. On the contrary, this study showed that participants were more motivated by messages that made no mention of the word 'obesity' but focused on healthy behaviors without relating them to body weight.

Efforts that promote weight loss to 'improve' one's appearance can perpetuate weight bias if their messages equate thinness with health and/or beauty. Promoting weight loss to achieve these standards could promote unhealthy preoccupations with weight and size and the 
development of disordered eating patterns. It has been shown that media images of thin bodies play an important role in the etiology of eating disorders [39].

\section{(5) Weight bias is a manifestation of social inequity}

Social inequity refers to unequal access, opportunities, rewards, and therefore outcomes for different social groups that are unfair and unjust [40, 41]. Sociallydefined groups of people, such as people defined by their high or low body weight, can be treated unequally. Weight bias is a manifestation of social inequity because people belonging to the 'large bodies' social group are not treated equally to the 'small bodies' social group in various sectors in society (e.g., employment, education, healthcare) $[15,42]$. People belonging to the 'small bodies' social group have more privileges and are rewarded differently than people belonging to the 'large bodies' social group [15, 42]. Stigma has been identified as a fundamental cause of population health inequities [43]. Weight bias contributes to harm and violation of human rights [44], in that prevalent stereotypes are often unchallenged and people living with obesity are vulnerable to unfair treatment simply because they have large bodies [15]. Numerous studies show that children and adults living with obesity are treated unequally because of their size at school, at work, in interpersonal relationships and within the healthcare system [15]. It has been argued that weight bias is a socially acceptable form of prejudice today [45]. To illustrate, whereas "race, national or ethnic origin, colour, religion, sex, age or mental or physical disability" are protected in the Canadian Charter of Rights and Freedoms [46], weight is not. Similarly, there are no federal laws prohibiting weight bias in other countries including the United States [47], despite public support for laws prohibiting weight discrimination $[22,48]$.

Although more research is needed on the root causes of weight bias [49], one of the causal explanations for having weight-biased attitudes is holding the belief that obesity is 'controllable' by individuals [50]. Although individual choice and agency are recognized in weight management, a society that highly values individualism may greatly overstate the 'controllability' of obesity which sets the stage for weight bias. To some extent, body weight has a biological underpinning whereby most individuals who lose weight cannot sustain weight loss over the long term [51, 52]. Furthermore, several national organizations have recognized obesity as a chronic disease, including the American Medical Association [53] and the Canadian Medical Association [54], supported by research evidence showing the genetic basis and the complexity of obesity lies beyond the individual $[8,55]$. As noted above, evidence of the prevalence and consequences of weight bias suggest that treating people disrespectfully because of their weight is harmful to their physical and mental health and it does not result in positive behavior change related to weight loss $[56,57]$. Therefore, weight bias does not appear to be justified as a public health tactic to address obesity [22]. All people, regardless of body size, deserve respect, equity, and dignity, and to live without stigma and discrimination.

\section{(6) Action on weight bias requires an upstream, population-level approach}

Since weight bias can be experienced across the weight spectrum, and experiencing weight bias can lead to the development and persistence of weight and body-related concerns across the population, a population-level approach is necessary to ensure respect for people of all shapes and sizes. The traditional approach to reducing stigma associated with obesity has been to raise awareness and educate individuals primarily in clinical contexts [58] by improving knowledge on the multifactorial etiology of obesity, increasing awareness of weight bias and its negative implications, and providing sensitivity training on the prevention and management of obesity. It is unclear whether these initiatives promote positive behaviour changes or worsen attitudes about weight over the long term. Evidence is limited about whether these sorts of changes are sustainable and whether they impact populations by addressing deeper, fundamental causes of weight bias. Adopting a population health approach allows us to build on the existing prevention literature that is mostly focused on downstream approaches to prevention $[59,60]$.

The Nuffield Council on Bioethics' intervention ladder [61] (Table 1) illustrates the breadth of intervention activities that one could consider within a population/public health approach. In that framework, educational initiatives providing information are identified as the second lowest level, which corresponds to more limited capacity to positively impact population health and health inequities. We argue that upstream populationlevel approaches to addressing weight bias, such as activities higher up on the intervention ladder, should be considered, with the potential benefits being balanced against the increasing level of intrusion or coercion. Prevention efforts should not be giving conflicting messages to confuse the population but should focus on promoting health and wellbeing. Examples of higher-level intervention ideas aligned with an upstream population health approach to wellbeing across the spectrum of weight-related issues are provided in Table 1. To complement suggested activities in Table 1, it is important for people working in the fields of obesity and eating disorders to reflect on their own assumptions. 
Table 1 Examples of interventions to prevent weight bias, organized using the Nuffield Council on Bioethics' intervention ladder as a framework [52]

\begin{tabular}{|c|c|}
\hline Government action & Examples in the field of weight bias (Research locations) \\
\hline \multirow[t]{6}{*}{ Restrict choice. } & - Develop legislation to prohibit weight discrimination [48] (U.S.A., Canada, Australia, Iceland) \\
\hline & $\begin{array}{l}\text { - Implement anti-discrimination laws against bullying in schools and weight discrimination in the employment } \\
\text { and healthcare sectors [62] (U.S.A.) }\end{array}$ \\
\hline & $\begin{array}{l}\text { - Mandatory post-secondary curricula and appropriate training on weight-related issues for pre-service student } \\
\text { teachers, health professionals and public health practitioners }[58,62,63] \text { (Canada, U.S.A., Iceland, Australia) }\end{array}$ \\
\hline & - Formal training for coaches to prevent eating disorders in sports [62] (U.S.A.) \\
\hline & $\begin{array}{l}\text { - Mandatory implementation of evidence-based body appreciation, media literacy and eating disorder prevention } \\
\text { programs in schools }[62,64] \text { (U.S.A.) }\end{array}$ \\
\hline & $\begin{array}{l}\text { - Ban digital modification of images that glamorize thinness in women and muscularity in men in the } \\
\text { media [65] (Australia) }\end{array}$ \\
\hline Guide choice through disincentives. & $\begin{array}{l}\text { - Implement penalties for evidence of weight discrimination in employment, healthcare and education sectors } \\
\text { (e.g., charging schemes in the employment and healthcare sectors, exclusion from extra-curricular activities } \\
\text { for youth in schools) }\end{array}$ \\
\hline Guide choice through incentives. & $\begin{array}{l}\text { - Offer awards, fiscal or other incentives for the promotion of wellbeing and body inclusivity in the education, } \\
\text { healthcare and employment sectors (e.g., a school board could offer an award or recognition for schools that } \\
\text { implement body inclusivity in their teaching and learning practices) }\end{array}$ \\
\hline \multirow[t]{2}{*}{$\begin{array}{l}\text { Guide choice through changing the } \\
\text { default policy. }\end{array}$} & $\begin{array}{l}\text { - Devise media and journalism guidelines for prohibiting gender-based and weight-based stereotypes in the } \\
\text { media [66] (U.S.A.) (e.g., stop portraying women of size eating ice cream to cope with mental health issues) }\end{array}$ \\
\hline & - Depict positive stereotypes of people living with obesity in the media [67] (U.S.A.) \\
\hline \multirow[t]{2}{*}{ Enable choice. } & $\begin{array}{l}\text { - Modify the built environment to accommodate individuals of all weights [68] (U.S.A.) (e.g., chairs in waiting } \\
\text { rooms, staircases, airplane seats, hospital beds, clothing uniforms and exercise equipment) }\end{array}$ \\
\hline & $\begin{array}{l}\text { - Offer an evidence-based school program geared towards positive body image, acceptance of body diversity } \\
\text { and prevention of weight-related issues [64] (U.S.A.) }\end{array}$ \\
\hline \multirow[t]{2}{*}{ Provide information. } & $\begin{array}{l}\text { - Create flyers and posters that promote positive body image and body diversity and distribute them in } \\
\text { schools }\end{array}$ \\
\hline & - Disseminate population health campaigns to address weight bias [69] (Australia) \\
\hline \multirow{2}{*}{$\begin{array}{l}\text { Do nothing or simply monitor the } \\
\text { situation }\end{array}$} & - Monitor the prevalence of weight bias in different sectors (i.e., education, healthcare, employment) \\
\hline & - Do nothing \\
\hline
\end{tabular}

Note: Strategies for evaluation of the effectiveness and cost of these initiatives must also be incorporated

\section{Conclusion}

Traditionally, weight-related issues such as obesity and eating disorders have been treated as separate and distinct research and practice domains. This commentary argues that the concept of weight bias is an important variable when considering wellbeing across the spectrum of weightrelated issues. Sustainable reductions in weight bias at a population level necessitate substantive upstream modifications and collaborative efforts in multiple settings.

\section{Acknowledgements}

ASA kindly acknowledges the Canadian Institutes of Health Research for her Banting Postdoctoral Fellowship and her previous Eyes High Postdoctoral Fellowship from the University of Calgary. LM gratefully acknowledges support from an Applied Public Health Chair award funded by CIHR Institute of Population and Public Health and Institute of Musculoskeletal Health and Arthritis, the Public Health Agency of Canada, and Alberta Innovates - Health Solutions.

\section{Funding}

ASA is funded by a Banting Postdoctoral Fellowship from the Canadian Institutes of Health Research (CIHR) and previously by an Eyes High Postdoctoral Fellowship from the University of Calgary. LM has support from an Applied Public Health Chair award funded by CIHR Institute of Population and Public Health and Institute of Musculoskeletal Health and Arthritis, the Public Health Agency of Canada, and Alberta Innovates - Health Solutions.
The funding bodies had no roles in writing the manuscript, the design, collection, analysis, or interpretation of the content herein.

\section{Availability of data and material \\ Not applicable.}

\section{Authors' contributions}

All authors conceived the topic of this article. ASA led the writing. SRM, KVR and LM provided analytical input and helped draft and edit the manuscript. All authors read and approved the final manuscript.

\section{Competing interests}

The authors declare that they have no competing interests.

\section{Consent for publication}

Not applicable.

Ethics approval and consent to participate Not applicable.

\section{Author details}

${ }^{1}$ Werklund School of Education, University of Calgary, 2500 University Dr NW, T2N 1N4 Calgary, AB, Canada. 'Department of Psychology, University of Calgary, 2500 University Drive NW, T2N 1N4 Calgary, AB, Canada.

${ }^{3}$ Community Health Sciences, Cumming School of Medicine, University of Calgary, TRW Building, 3rd Floor, 3280 Hospital Drive NW, T2N 4Z6 Calgary, $\mathrm{AB}$, Canada. 


\section{Received: 28 January 2016 Accepted: 21 July 2016}

Published online: 07 November 2016

\section{References}

1. Haines J, Neumark-Sztainer D. Prevention of obesity and eating disorders: consideration of shared risk factors. Health Educ Res. 2006;21(6):770-82. doi:10.1093/her/cyl094.

2. Neumark-Sztainer D. Can we simultaneously work toward the prevention of obesity and eating disorders in children and adolescents? Int J Eat Disord. 2005;38(3):220-7. doi:10.1002/eat.20181.

3. Stice E, Marti CN, Durant S. Risk factors for onset of eating disorders: evidence of multiple risk pathways from an 8-year prospective study. Behav Res Ther. 2011:49(10):622-7. doi:10.1016/j.brat.2011.06.009.

4. Sanchez-Carracedo D, Neumark-Sztainer D, Lopez-Guimera G. Integrated prevention of obesity and eating disorders: barriers, developments and opportunities. Public Health Nutr. 2012;15(12):2295-309. doi:10.1017/ S1368980012000705.

5. Irving LM, Neumark-Sztainer D. Integrating the prevention of eating disorders and obesity: feasible or futile? Prev Med. 2002;34(3):299-309. doi:10.1006/pmed.2001.0997.

6. Russell-Mayhew S. Stop the war on weight; eating disorder and obesity prevention working together toward health. Eat Disord J Treat Prev. 2006;14(3):253-63

7. Washington RL. Childhood obesity: issues of weight bias. Preventing chronic disease. 2011. http://www.cdc.gov/pcd/issues/2011/sep/10_0281.htm. Accessed 20 Sept 2013.

8. Frood S, Johnston LM, Matteson CL, Finegood DT. Obesity, complexity, and the role of the health system. Curr Obes Rep. 2013;2:320-6. doi:10.1007/ s13679-013-0072-9.

9. McLaren L, de Groot J, Adair CE, Russell-Mayhew S. Socioeconomic position, social inequality, and weight-related issues. In: McVey G, Levine M, Piran N, Ferguson B, editors. Preventing eating-related and weight-related disorders collaborative research, advocacy, and policy change. Waterloo: Wilfred Laurier University Press; 2012

10. McLaren L. Social and economic determinants of obesity. 4th ed. Handbook of Obesity. London: Informa Healthcare; In press.

11. Tesh SN. Hidden arguments: political ideology and disease prevention policy. New Brunswick: Rutgers University Press; 1988 (Introduction); (Chapt 2: Twentieth century debates).

12. Puhl R, Luedicke J, Peterson JL. Public reactions to obesity-related health campaigns: a randomized controlled trial. Am J Prev Med. 2013;45(1):36-48. doi:10.1016/j.amepre.2013.02.010.

13. Puhl R, Suh Y. Stigma and eating and weight disorders. Curr Psychiatry Rep. 2015:17(3):552. doi:10.1007/s11920-015-0552-6

14. Andreyeva T, Puhl RM, Brownell KD. Changes in perceived weight discrimination among Americans, 1995-1996 through 2004-2006. Obesity (Silver Spring). 2008;16(5):1129-34. doi:10.1038/oby.2008.35.

15. Puhl RM, Heuer CA. The stigma of obesity: a review and update. Obesity (Silver Spring). 2009;17(5):941-64. doi:10.1038/oby.2008.636.

16. Neumark-Sztainer D, Falkner N, Story M, Perry C, Hannan PJ, Mulert S. Weight-teasing among adolescents: correlations with weight status and disordered eating behaviors. Int J Obes Relat Metab Disord. 2002;26(1):12331. doi:10.1038/sj.ijo.0801853.

17. Pearl RL, White MA, Grilo CM. Weight bias internalization, depression, and self-reported health among overweight binge eating disorder patients. Obesity (Silver Spring). 2014;22(5):E142-8. doi:10.1002/oby.20617.

18. Pearl RL, White MA, Grilo CM. Overvaluation of shape and weight as a mediator between self-esteem and weight bias internalization among patients with binge eating disorder. Eat Behav. 2014:15(2):259-61. doi:10. 1016/j.eatbeh.2014.03.005.

19. Flegal KM, Kit BK, Orpana H, Graubard BI. Association of all-cause mortality with overweight and obesity using standard body mass index categories: a systematic review and meta-analysis. JAMA. 2013;309(1):71-82. doi:10.1001/ jama.2012.113905.

20. Kuk JL, Ardern Cl, Church TS, Sharma AM, Padwal R, Sui X, et al. Edmonton Obesity Staging System: association with weight history and mortality risk. Appl Physiol Nutr Metab. 2011;36(4):570-6. doi:10.1139/h11-058.

21. Padwal RS, Pajewski NM, Allison DB, Sharma AM. Using the Edmonton obesity staging system to predict mortality in a population-representative cohort of people with overweight and obesity. CMAJ. 2011:183(14):E105966. doi:10.1503/cmaj.110387.
22. Puhl RM, Heuer CA. Obesity stigma: important considerations for public health. Am J Public Health. 2010;100(6):1019-28. doi:10.2105/AJPH.2009. 159491.

23. Sutin $A R$, Stephan $Y$, Terracciano A. Weight discrimination and risk of mortality. Psychol Sci. 2015;26(11):1803-11. doi:10.1177/0956797615601103.

24. Puhl RM, Brownell KD. Confronting and coping with weight stigma: an investigation of overweight and obese adults. Obesity (Silver Spring). 2006; 14(10):1802-15. doi:10.1038/oby.2006.208

25. McPhail D. What to do with "The Tubby Hubby"? "Obesity", the crisis of masculinity, and the reification of the nuclear family in early Cold War Canada. Antipode. 2009:41:1021-50.

26. Latner JD, Stunkard AJ. Getting worse: the stigmatization of obese children. Obes Res. 2003;11(3):452-6. doi:10.1038/oby.2003.61.

27. Vartanian LR, Novak SA. Internalized societal attitudes moderate the impact of weight stigma on avoidance of exercise. Obesity (Silver Spring). 2011 19(4):757-62. doi:10.1038/oby.2010.234.

28. Pearl RL, Puhl RM, Dovidio JF. Differential effects of weight bias experiences and internalization on exercise among women with overweight and obesity. J Health Psychol. 2015;20(12):1626-32. doi:10.1177/ 1359105313520338

29. Almeida L, Savoy S, Boxer P. The role of weight stigmatization in cumulative risk for binge eating. J Clin Psychol. 2011;67(3):278-92. doi:10.1002/jclp. 20749.

30. Durso LE, Latner JD, Hayashi K. Perceived discrimination is associated with binge eating in a community sample of non-overweight, overweight, and obese adults. Obes Facts. 2012;5(6):869-80. doi:10.1159/000345931.

31. Puhl RM, Moss-Racusin CA, Schwartz MB. Internalization of weight bias: implications for binge eating and emotional well-being. Obesity (Silver Spring). 2007;15(1):19-23. doi:10.1038/oby.2007.521.

32. Wilson CP. The fear of being fat and anorexia nervosa. Int J Psychoanal Psychother. 1982;9:233-55.

33. Forhan $\mathrm{M}$, Risdon $\mathrm{C}$, Solomon P. Contributors to patient engagement in primary health care: perceptions of patients with obesity. Prim Health Care Res Dev. 2013:14(4):367-72 doi:10.1017/S1463423612000643.

34. Pickering RP, Goldstein RB, Hasin DS. Temporal relationships between overweight and obesity and DSM-IV substance use, mood, and anxiety disorders: results from a prospective study, the National epidemiologic survey on alcohol and related conditions. J Clin Psychiatry. 2011:72: 1494-502.

35. Friedman KE, Reichmann SK, Costanzo PR, Zelli A, Ashmore JA, Musante GJ. Weight stigmatization and ideological beliefs: relation to psychological functioning in obese adults. Obes Res. 2005;13(5):907-16.

36. Rosenberger PH, Henderson KE, Bell RL, Grilo CM. Associations of weightbased teasing history and current eating disorder features and psychological functioning in bariatric surgery patients. Obes Surg. 2007; 17(4):470-7.

37. Puhl RM. Weight stigmatization toward youth: a significant problem in need of societal solutions. Childhood Obes. 2011;7:359-63.

38. Puhl R, Peterson JL, Luedicke J. Fighting obesity or obese persons? Public perceptions of obesity-related health messages. Int J Obes (Lond). 2013; 37(6):774-82. doi:10.1038/ijo.2012.156.

39. Stice E, Shaw HE. Adverse effects of the media portrayed thin-ideal on women and linkages to bulimic symptomatology. J Soc Clin Psychol. 1994; 13:288-308.

40. Whitehead M. The concepts and principles of equity and health. Int J Health Serv. 1992;22:429-45.

41. National Collaborating Centre for Determinants of Health. Let's Talk Health Equity. http://nccdh.ca/images/uploads/Lets_Talk_Health_Equity_English.pdf [Accessed 24 May 2016].

42. Rudolph CW, Wells CL, Weller MD, Baltes BB. A meta-analysis of empirical studies of weight-based bias in the workplace. J Vocat Behav. 2009:74(1):1-10

43. Hatzenbuehler ML, Phelan JC, Link BG. Stigma as a fundamental cause of population health inequalities. Am J Public Health. 2013;103(5):813-21. doi: 10.2105/AJPH.2012.301069

44. O'Hara LGJ. Human rights casualties from the "War on Obesity": Why focusing on body weight is inconsistent with a human rights approach to health. Fat Stud. 2013:1:32-46.

45. Pomeranz JL. A historical analysis of public health, the law, and stigmatized social groups: the need for both obesity and weight bias legislation. Obesity (Silver Spring). 2008;16 Suppl 2:S93-103. doi:10.1038/oby.2008.452. 
46. Department of Justice Canada. The Constitution Act, 1982. The Canadian Charter of Rights and Freedoms. http://laws-lois.justice.gc.ca/eng/const/ page-15.html. [Accessed 31 July 2016].

47. Puhl RM, Heuer C, Sarda V. Framing messages about weight discrimination: impact on public support for legislation. Int J Obes (Lond). 2011;35(6):86372. doi:10.1038/ijo.2010.194.

48. Puhl RM, Latner JD, O'Brien KS, Luedicke J, Danielsdottir S, Salas XR. Potential policies and laws to prohibit weight discrimination: public views from 4 countries. Milbank Q. 2015;93(4):691-731. doi:10.1111/ 1468-0009.12162.

49. Alberga AS, Russell-Mayhew S, von Ranson K, McLaren L, Ramos-Salas X, Sharma AM. Future research in weight bias: what next? Obesity. 2016;24: 1207-9. doi:10.1002/oby.21480.

50. Crandall R, Reser A. Attributions and weight-based prejudice. In: Brownell K, Puhl R, Schwartz M, Rudd L, editors. Weight bias: nature, consequences and remedies. New York: Guildford Press; 2005.

51. Sumithran P, Proietto J. The defence of body weight: a physiological basis for weight regain after weight loss. Clin Sci (Lond). 2013;124(4):231-41. doi: 10.1042/CS20120223

52. Kraschnewski JL, Boan J, Esposito J, Sherwood NE, Lehman EB, Kephart DK, Sciamanna CN. Long-term weight loss maintenance in the United States. Int J Obes (Lond). 2010;34:1644-54. doi:10.1038/ijo.2010.94.

53. Pollack A. A.M.A. Recognizes obesity as a disease. 2015 [Internet Retrieved March 2, 2016: http://www.nytimes.com/2013/06/19/business/amarecognizes-obesity-as-a-disease.html]. Accessed 31 July 2016.

54. Rich P. CMA recognizes obesity as a disease. 2015 [Internet Retrieved March 2, 2016: https://www.cma.ca/En/Pages/cma-recognizes-obesity-as-a-disease. aspx]. Accessed 31 July 2016.

55. Bouchard C, Tremblay A, Despres JP, Nadeau A, Lupien PJ, Theriault G, et al. The response to long-term overfeeding in identical twins. N Engl J Med. 1990;322(21):1477-82. doi:10.1056/NEJM199005243222101.

56. Puhl RM, Luedicke J, Heuer C. Weight-based victimization toward overweight adolescents: observations and reactions of peers. J Sch Health. 2011;81(11):696-703. doi:10.1111/j.1746-1561.2011.00646.x.

57. Schvey NA, Puhl RM, Brownell KD. The impact of weight stigma on caloric consumption. Obesity (Silver Spring). 2011;19(10):1957-62. doi:10.1038/oby. 2011.204.

58. Danielsdottir S, O'Brien KS, Ciao A. Anti-fat prejudice reduction: a review of published studies. Obes Facts. 2010;3(1):47-58. doi:10.1159/000277067.

59. Pratt BM, Woolfenden S. Interventions for preventing eating disorders in children and adolescents. Cochrane Database Syst Rev. 2002;2, CD002891. doi:10.1002/14651858.CD002891.

60. Waters E, de Silva-Sanigorski A, Burford BJ, Brown T, Campbell KJ, Gao Y, Armstrong R, Prosser L, Summerbell CD. Interventions for preventing obesity in children. Cochrane Database Syst Rev. 2011;12, CD001871. doi:10. 1002/14651858.CD001871.pub3.

61. Nuffield Council on Bioethics. Chapter 3: policy process and practice. Public health: ethical issues. London: Nuffield Council; 2007. p. 41.

62. Puhl RM, Neumark-Sztainer D, Austin SB, Luedicke J, King KM. Setting policy priorities to address eating disorders and weight stigma: views from the field of eating disorders and the US general public. BMC Public Health. 2014;14:524. doi:10.1186/1471-2458-14-524.

63. McVey GL, Walker KS, Beyers J, Harrison HL, Simkins SW, Russell-Mayhew S. Integrating weight bias awareness and mental health promotion into obesity prevention delivery: a public health pilot study. Prev Chronic Dis. 2013;10, E46. doi:10.5888/pcd10.120185.

64. Ciao AC, Loth K, Neumark-Sztainer D. Preventing eating disorder pathology: common and unique features of successful eating disorders prevention programs. Curr Psychiatry Rep. 2014;16(7):453. doi:10.1007/ s11920-014-0453-0.

65. Australian Government. The National Advisory Group on Body Image. The voluntary industry code of conduct on body image. 2009.

66. McClure KJ, Puhl RM, Heuer CA. Obesity in the news: do photographic images of obese persons influence antifat attitudes? J Health Commun. 2011;16(4):359-71. doi:10.1080/10810730.2010.535108.

67. Pearl RL, Puhl RM, Brownell KD. Positive media portrayals of obese persons: impact on attitudes and image preferences. Health Psychol. 2012;31(6):8219. doi:10.1037/a0027189.

68. Aldrich T, Hackley B. The impact of obesity on gynecologic cancer screening: an integrative literature review. J Midwifery Womens Health. 2010;55(4):344-56. doi:10.1016/j.jmwh.2009.10.001.
69. Star A, Hay P, Quirk F, Mond J. Perceived discrimination and favourable regard toward underweight, normal weight and obese eating disorder sufferers: implications for obesity and eating disorder population health campaigns. BMC Obes. 2015;2:4. doi:10.1186/s40608-014-0032-2.

\section{Submit your next manuscript to BioMed Central and we will help you at every step:}

- We accept pre-submission inquiries

- Our selector tool helps you to find the most relevant journal

- We provide round the clock customer support

- Convenient online submission

- Thorough peer review

- Inclusion in PubMed and all major indexing services

- Maximum visibility for your research

Submit your manuscript at www.biomedcentral.com/submit
C Biomed Central 